\title{
OS PROFESSORES DE ENSINO MÉDIO E SUAS CONCEPÇÕES SOBRE O CURRÍCULO DE QUÍMICA DE SÃO PAULO
}

\author{
Adriano Luiz de Souza, Maria Eliza Nogueira Oliveira \\ Universidade do Oeste Paulista - UNOESTE, Programa de Pós-Graduação em Educação, Presidente Prudente, SP. E-mail: \\ drsou33@yahoo.com.br.
}

\begin{abstract}
RESUMO
Vinculado a linha de pesquisa Políticas Públicas em Educação, Práticas Educativas e Diversidade do Programa de Mestrado em Educação da Universidade do Oeste Paulista (UNOESTE), esta pesquisa objetiva compreender a forma com que professores de Química do Ensino Médio, de um município de médio porte do interior do estado de São Paulo, percebem o currículo de Ciências da Natureza. Trata-se de uma investigação de abordagem qualitativa por meio de um questionário com questões abertas e fechadas, onde se pretende traçar o perfil pessoal e profissional dos docentes, bem como obter informações sobre o currículo de Química implantado pelo estado. Os dados serão tratados via Análise de Discurso.
\end{abstract}

Palavras-chave: Currículo de Química; Concepção de Professores; Análise de Discurso.

\section{THE TEACHERS OF MEDIUM EDUCATION AND ITS CONCEPTIONS ON THE CURRICULUM OF CHEMISTRY OF SÃO PAULO}

\begin{abstract}
Linked to the research line Public Policies in Education, Educational Practices and Diversity of the Master's Program in Education of Universidade do Oeste Paulista (UNOESTE), this research aims to understand the way in which professors of Chemistry of High School, of a medium-sized municipality of the interior of the state of São Paulo, perceive the curriculum of Natural Sciences. It is a qualitative research through a questionnaire with open and closed questions, where it is sought to trace the personal and professional profile of teachers, as well as to obtain information about the Chemistry curriculum implemented by the state. The data will be processed via Discourse Analysis.
\end{abstract}

Keywords: Chemistry Curriculum; Teacher Conception; Discourse Analysis. 


\section{INTRODUÇÃO}

Nem sempre é fácil perceber os efeitos que os fenômenos das ciências naturais causam em nosso cotidiano; para Soares (2016) "este é o momento em que se reflete sobre as relações possíveis entre conhecimentos tecnológicos e científicos, os conhecimentos considerados escolares e, os conhecimentos tomados como cotidianos".

Este questionamento traz a necessidade para repensarmos suas contribuições em nossa vida. Assim o processo ensino aprendizagem das ciências naturais deve envolver, de forma combinada, o desenvolvimento de conhecimentos práticos, contextualizados, e que respondam às necessidades da vida contemporânea.

Nos dias de hoje, mudanças curriculares e adesão de novas propostas no que se refere a Educação, são notícias frequentes na mídia. Guimarães (2016) em entrevista a revista Época, diz que "defende há muito tempo uma completa reformulação do ensino médio brasileiro". Os jovens de hoje vivem utilizando redes sociais e smartphones; estas tecnologias não os fazem se identificar com o modelo de ensino atual.

Em 1998, O Ministério da Educação (ME) já afirmava a necessidade dessa reformulação em virtude do aumento do número de matrículas na primeira série do Ensino Médio. (LOPES, 1998).

Isso ocorreu em função do desemprego crescente na época que tornou o mercado de trabalho cada vez mais seletivo e competitivo. A referida autora acima, nos traz que, nessa época o ME encaminhou uma proposta para organização curricular e da base nacional comum do ensino médio.

Krasilchik (2000), coloca que o movimento de reforma da escola é um processo de mudança nacional com uma forte tendência à volta ao papel centralizador do Estado para emissão de normas e regulamentos. As concepções que trazem distintos conceitos de currículo nem sempre são oficializadas como políticas educacionais no Brasil.

De acordo com Pacheco (1996), o termo currículo é proveniente do vocábulo latino currere (significa caminho, jornada, percurso a seguir) e pressupõe duas ideias: 1) uma de sequência ordenada de conteúdos; 2) noção de totalidade de plano de estudo.

Em outra definição, Silva (2005) traz que um currículo busca precisamente modificar as pessoas que vão seguir aquele currículo.

Entretanto o currículo apresenta múltiplos aspectos, a qual suas fases de construção e progresso são interativos e ao mesmo tempo, interdependentes.

Silva (2005) apresenta uma visão geral das teorias do currículo, através de diversos estudos e autores que se apresentam a origem do campo do currículo, incluindo as teorias tradicionais, críticas e pós-críticas.

As Teorias Tradicionais são caracterizadas por priorizar questões convencionais e técnicas na construção e organização curricular e apresentam uma cientificidade desinteressada das questões político-sociais, constituídas em três vertentes distintas: a clássica, a progressiva e a tecnocrática.

As Teorias Críticas superam a idéia de um currículo homogêneo e meramente prescritivo e argumentam que o mesmo reflete intencionalidades de diferentes ordens, entre elas: política, social e econômica na constituição dos saberes.

As Teorias Pós Críticas questionam as formas dominantes de conhecimento, sendo denominadas teorias da desconfiança. Busca destacar o resultado do currículo e não as diretrizes de como o currículo foi elaborado. A partir da seleção de conhecimentos, recorrentes de toda teoria, discorre sobre a ligação poder e currículo, ou seja, para que deve ser ensinado. Em relação a organização curricular, além dos questionamentos do "como" e o quê" acrescenta-se "para quê".

Conforme Silva (2005), a teoria crítica do currículo busca entender o que o currículo faz e questiona as formas dominantes de conhecimento. A análise das reformas curriculares nas últimas 
décadas, convergem para a atenção nas relações existentes entre conhecimento, currículo e sua materialização no decorrer do dia a dia educacional.

Oliveira (2009) coloca que, o campo do currículo tem tomado a reforma como objeto de estudo, porém pouco se discute seu significado. A análise do significado é primordial para um processo de avaliação que experiencia essas reformass educacionais.

Sacristán (2000) se posiciona sobre o currículo afirmando que este pode ser refletido e analisado a partir de cinco perspectivas:

- ponto de vista sobre sua função social como ponte entre a sociedade e a escola;

- projeto ou plano educativo, pretenso ou real composto de diferentes aspectos;

- currículo como expressão formal e material desse projeto que deve apresentar, sob determinado formato, seus conteúdos, suas orientações e suas sequências para abordá-lo;

- o currículo como um campo prático. Entende-lo assim supõe a possibilidade de:

1) analisar os processos instrutivos e a realidade da prática a partir de uma perspectiva que lhes dota de conteúdo; 2 ) estudá-lo como território de inserção de práticas diversas que não se referem apenas aos processos de tipo pedagógico, interações e comunicações educativas; 3 ) sustentar o discurso sobre a interação entre a teoria e a prática em educação;

- o currículo como um tipo de atividade discursiva acadêmica e pesquisadora sobre todos esses temas. (SACRISTÁN, 2000, p. 14 e 15).

Nessa perspectiva é possível compreender a prática educativa das instutuições promotoras de saberes e as funções sociais da escola; Pacheco (1996) nos mostra que a construção do currículo deve envolver a parceria de todos: pais, professores e gestores, pois este insrumento não é de domínio de algum setor especial, mas de construção da coletividade que almeja atender as necessidades da comunidade e a busca da qualidade educacional.

Gomes e Lopes (2015) apresentam um estudo com a temática o currículo na sociedade neoliberal, com o objetivo de compreender o que é currículo e qual sua finalidade neste contexto. Como conclusão, ao discutir seu significados ne escola de educação básica pública, a percepção de currículo manifesta-se de maneira equivocada, limitando-se a um documento orientador de seleção de conteúdos e o prevalecimento de percepções conservadoras e superficialidade no conhecimento. (GOMES e LOPES, p. 85, 2015).

Inicialmente, ao implantar a proposta curricular no estado de São Paulo, ocorreu a distribuição nas escolas estaduais do "Jornalzinho do Estado" pela Secretaria de Educação. Este instrumento apresentava notícias, sugestões de atividades e curiosidades sobre as disciplinas a serem desenvolvidas pelos professores da Educação Básica. Segundo Zan (2012), para o ensino médio foram produzidas cinco revistas (Língua Portuguesa, Matemática, Física/Química/Biologias, História/Geografia/Filosofia e Arte/Língua Estrangeira Moderna/Educação Física). Para viabilizar a utilização do material, foi disponibilizado aos professores orientações por meio de vídeos formativos. Todavia, para a autora, a proposta representou o professor como "aplicador da proposta", padronizou a aprendizagem, "desconsiderando tantas pesquisas que apontam para esta como uma atividade de apropriação do conhecimento que é cultural, histórica, social e singular" (ZAN, 2012, p. 66).

Cação (2010) apresenta um ensaio que problematiza como inovações e reformas educativas afetam a construção curricular na escola pública. A autora entende que a proposta curricular visou a homogeneização do conhecimento escolar e das práticas curriculares, encerrando a noção de currículo como um produto. Nesse sentido, é possível questionar se a então proposta (que dois anos mais tarde foi considerada como currículo oficial) preservou a autonomia e identidade das escolas nas quais foi implantada, respeitando seu Projeto Político Pedagógico. 
Em 2010 a proposta foi adotada como currículo oficial do estado de São Paulo. O currículo se completa com um conjunto de documentos dirigidos aos Professores e alunos: os cadernos do Professor e do aluno. São organizados por disciplina/série(ano)/semestre, em dois volumes anuais para cada série. Nesses documentos são apresentados tópicos denominados de "Situação de Aprendizagem" para orientar o trabalho do professor no ensino dos conteúdos disciplinares específicos e a aprendizagem do aluno. (SÃO PAULO, 2010).

Ao problematizarem o currículo de química, Mortimer, Machado e Romanelli (2000) argumentam que os currículos tradicionais enfatizam apenas conceitos que devem ser transmitidos para os alunos, o que descontextualiza e "descola" o ensino da realidade dos estudantes. A quantidade de conceitos presentes no currículo também é alvo de crítica dos autores, pois, segundo o que defendem, esse excesso não permite com que o aluno assimile o conhecimento em tão pouco tempo e o relacione com uma estrutura mais ampla que dê significado ao aprendizado.

Em abril de 2017, o Ministério da Educação e Cultura entregou a versão final da Base Nacional Comum Curricular (BNCC) ao Conselho Nacional de Educação (CNE). Tenta-se com isso, organizar o sistema de ensino no Brasil.

Macedo (2016) focaliza o debate sobre a BNCC através de duas idéias antagônicas: o conhecimento para fazer algo e o conhecimento em si. A prevalência de currículos disciplinares, que se propõem a mimetizar na escola os campos científicos com maior ou menor consciência dos processos de recontextualização, indica a importância do conhecimento em si. Porém, ao discordar da BNCC, relata que esta é uma aposta que constitui um desafio mais difícil que produzir uma lista de conteúdos ou de capacidades de fazer. Envolve uma valorização da educação e não o controle que a destrói como empreitada subjetiva.

Para a disciplina de Química, as proposituras do BNCC para a organização do currículo se constituem de maneira diferenciada das atualmente implantadas para o Ensino Médio. A organização curricular da disciplina passaria a ser dividida em seis unidades onde a abordagem das unidades seguiria as seguintes dimensões: conhecimento conceitual; contextualização histórica, social e cultural; processos e práticas investigativas; linguagem desta ciência e da natureza (BRASIL, 2016).

A presente proposta objetiva problematizar o currículo de Química da rede estadual pública do estado de São Paulo a partir da concepção de professores. A compreensão e reflexão sobre o currículo implantado são primordiais para entender a prática docente e quais conhecimentos são priorizados para o ensino de ciências nas escolas públicas paulistas.

\section{METODOLOGIA}

A abordagem qualitativa de investigação será utilizada como eixo norteador do estudo. Participaram dessa pesquisa 8 professores de Química das escolas públicas estaduais do município de Presidente Prudente, apresentando diferentes tempos de docência (desde recém formados até profissionais com duas ou três décadas de experiência no ensino).

Em uma pesquisa qualitativa os dados gerados são resultantes do contato do pesquisador com o fenômeno estudado e sua análise procura o entendimento do sentido que as pessoas atribuem ao objeto de estudo. A abordagem qualitativa permite compreender o processo de estabelecimento de relações sobre um objeto a partir dos sujeitos envolvidos em determinado contexto. Para Minayo (2001), este enfoque trabalha com o universo de significados, motivos, aspirações, crenças, valores e atitudes. Corresponde a um espaço mais profundo das relações, dos processos e dos fenômenos que não podem ser medidos.

Como instrumentos para geração de dados usar-se-á um questionário (com questões abertas e fechadas) que caracterizará os perfis: pessoal, docente e atuação profissional dos 
respondentes da pesquisa e, ainda, a concepção dos entrevistados sobre o currículo de Ciências da Natureza adotado para a rede estadual paulista de ensino.

O questionário pode ser definido como a técnica de coleta de dados composta por um número de questões apresentadas por escrito às pessoas, com vistas a conhecer opiniões, crenças, sentimentos, interesses, expectativas e ou situações vivenciadas por determinado sujeito ou grupo (GIL, 1999). O questionário apresenta as seguintes vantagens sobre as demais técnicas de coleta de dados:

- $\quad$ Possibilita atingir grande número de pessoas, mesmo que estejam dispersas numa área geográfica muito extensa, já que o questionário pode ser enviado pelo correio;

- Implica menores gastos com pessoal, posto que o questionário não exige o treinamento dos pesquisadores;

- $\quad$ Garante o anonimato das respostas;

- $\quad$ Permite que as pessoas o respondam no momento em que julgarem mais conveniente;

- Não expõe os pesquisadores à influência das opiniões e do aspecto pessoal do entrevistado. (GIL, 1999, p. 128).

Este projeto foi avaliado e aprovado pelo Comitê de Ética e Pesquisa da Universidade do Oeste Paulista (CEP/UNOESTE) sob o número 3535.

A análise dos dados gerados será realizada a partir das considerações sobre a Análise de Discurso (ORLANDI, 2009). Segundo Orlandi a Análise de Discurso baseia-se em duas vertentes: lugar e posição dos sujeitos. A primeira categoria vai dar conta dos lugares dos sujeitos frente a uma sociedade contendo relações hierarquizadas. A segunda aborda as projeções realizadas pelos sujeitos e seus momentos, como por exemplo, a antecipação do efeito do sentido causado pelo discurso no interlocutor. Desta concepção, surgem duas idéias que norteiam esta teoria: a ideia de que o sentido, assim como o sujeito, não é dado apriori, mas constituído no e pelo discurso; a noção do descentramento do sujeito que, embora fundamental, pois não existe discurso sem sujeito, perde sua essencialidade ao integrar-se no funcionamento dos enunciados (ORLANDI, 2009).

Serão analisadas nesse trabalho apenas as respostas as seguintes questões:

1) O que você pensa sobre o currículo?

2) Para você, o que é o currículo?

3) Você considera que o currículo apresenta limitações? Quais?

4) Você considera que o currículo apresenta potencialidades e vantagens? Quais?

\section{RESULTADOS E DISCUSSÃO}

Nesta fase, de acordo com alguns dados obtidos, resultante da análise primária das respostas fornecidas pelos professores entrevistados referentes à concepção de currículo (questões 1 e 2), chamou-nos a atenção o fato de que, para esses profissionais, o currículo vem sendo compreendido como "um conjunto de documentos que contém as coordenadas e orientações para o aprendizado", porém "deveria abordar mais o cotidiano dos estudantes". Isto demonstra que esses docentes, embora não se utilizem dos mesmos termos, apropriaram-se e vêm reproduzindo de forma sistemática, ao menos no âmbito discursivo, a definição oficial de currículo do Estado de São Paulo: "[...] documento que apresenta os princípios orientadores do currículo para uma escola capaz de promover as competências indispensáveis ao enfrentamento dos desafios sociais, culturais e profissionais do mundo contemporâneo". (SÃO PAULO, p. 7, 2010).

Observamos ainda a crítica dos docentes a respeito da ausência, por parte do Estado, de "suporte diversificado presencial para o currículo implantado, a não ser por Orientações Técnicas (OT) durante o decorrer do ano letivo", refletindo o anseio por meios mais eficientes de garantir a adaptação às exigências governamentais. 
Quando questionados sobre as limitações do currículo, dois docentes "colocam que o currículo não apresenta limitações" e seis docentes " nos respondem que o currículo foge da realidade do aluno; o material possui muito conteúdo para pouco tempo de aplicação; é totalmente desordenado frente ao livro texto; apresenta linguagem somente escrita e ausência desenho e foto". Através dessas falas evidencia-se que os docentes ainda não conseguem articular o uso do material do currículo com o livro didático, pois o currículo não segue a mesma ordem dos assuntos no livro didático.

Em relação as potencialidades e vantagens do currículo, seis docentes colocam "que a vantagem é a praticidade dos textos e ações"; "retirou conteúdos que não precisavam de aprofundamento, orientando até onde se pode chegar"; "que o aluno tem o mesmo conteúdo em todo o estado"; "o currículo mostra prática e pesquisa" e dois docentes "não veêm potencialidades e vantagens nesse currículo". A aplicação desses elementos levantados pelos docentes, dependem de alguns fatores, como o nível de aprendizado dos alunos e a formação do professor para uma melhor eficácia do currículo.

Resta-nos ainda compreender os sentidos que vêm sendo construídos pelos entrevistados diante do contexto por eles vivenciados atravessado por aberturas e restrições próprias de um processo dinâmico marcado por rupturas e continuidades.

\section{REFERÊNCIAS}

BRASIL. Base Nacional Comum Curricular (BNCC). Consulta Pública. Brasília, MEC/CONSED/UNDIME. Disponível em:

<http://basenacionalcomum.mec.gov.br/documentos/BNCC-APRESENTACAO.pdf>. Acesso em: 10 out 2016.

CAÇÃO, M. I. Proposta Curricular do Estado de São Paulo: Retorno do discurso regulativo da Tylerização na Educação Pública. Espaço do Currículo. João Pessoa, v.3, n.1, p. 380-394, mar./set. 2010.

GIL, A. C. Métodos e técnicas de pesquisa social. 5 a ed. São Paulo: Atlas, 1999.

GOMES, G. C. ; LOPES, R. S. P. Currículo, teoria crítica e neoliberalismo: a concepção dos educadores. In. Simpósio em pesquisa e pós graduação em educação: desafios atuais para a educação, 6., 2015, Paraná. Anais... Londrina, UEL, 20 a 22 de outubro, 2015, p. 85-99.

GUIMARAES, M. H. Revista Época. Entrevista. Disponível em:

< http://epoca.globo.com/ideias/noticia/2016/08/maria-helena-guimaraes-ha-um-tediogeneralizado-entre-os-alunos-do-ensino-medio.html>. Acesso em 20 de abr. 2017

KRASILCHIK, M. Reformas e realidade: o caso do ensino de ciências. São Paulo em Perspectiva, v. 14, no 1, p. 85- 93, jan./mar. 2000, https://doi.org/10.1590/S0102-88392000000100010.

LOPES, A. R. C. O Ensino Médio em Questão. Química Nova na Escola, São Paulo, no 7, p.11-14,mai. 1998.

MACEDO, E. Base Nacional Comum: a falsa oposição entre conhecimento para fazer algo e conhecimento em si. Educação em Revista, Belo Horizonte, v. 32, n. 2, p. 45-67, abr./jun. 2016, https://doi.org/10.1590/0102-4698153052.

MINAYO, M. C. S. (Org.). Pesquisa social: teoria, método e criatividade. Petrópolis:Vozes, 2001. 
MORTIMER, E. F. ; MACHADO, A. H.; ROMANELLI, L. I. A Proposta Curricular de Química do estado de Minas Gerais: fundamentos e pressupostos. Química Nova, São Paulo, v. 23, n. 2, p. 273-283, mar./abr. 2000, https://doi.org/10.1590/S0100-40422000000200022.

OLIVEIRA, O. V. Problematizando o significado de reforma nos textos de uma política de currículo. Currículo sem Fronteiras, v. 9, no 2, p. 68-78, jul./dez. 2009.

ORLANDI, E. P. Análise de Discurso: princípios e procedimentos. Campinas, SP: Pontes, 2009.

PACHECO, J. A. Currículo: teoria e práxis. Porto: Porto Editora, 1996.

SACRISTÁN, J. G. O Currículo: Uma reflexão sobre a prática. 3aedição, Porto Alegre:Artmed, 2000.

SÃO PAULO, Secretaria do Estado. Currículo do Estado de São Paulo: Ciências da Natureza e suas Tecnologias. São Paulo: SEE, 2010.

SÃO PAULO. Secretaria do Estado da Educação. Disponível em:

$<$ http ://www.educacao.sp.gov.br/curriculo>. Acesso em : 10 out. 2016.

SILVA, T. T. Documentos de Identidade: uma introdução às teorias do currículo. Autêntica, 2005.

ZAN, D. D. P. A Concepção de Ensino Médio e de Currículo expressa na Proposta de São Paulo. Horizontes, Itatiba, v. 30, n. 2, p. 59-68, jul./dez. 2012. 